doubt whether this is an improvement on the usual practice.

The chapters on the flora of East Africa, and those on the Zanzibari and other natives of the country, contain a large amount of information, and are thoroughly readable. The same may be said of the concluding chapter on the national movements and future prospects of British East Africa. The whole book is clearly and well written and liberally illustrated, and the atthor, who quotes - and quotes appositely-not only Shakespeare, Byron and Göethe, but also Carlyle, Buckle, and Rudyard Kipling, has evidently gleaned widely in literary as well as in scientific fields.

W. T. BI.ANFORD.

\section{THE MEETING OF THE INTERNATIONAL} COMMITTEE OF THE CARTE DU CIEL. ${ }^{1}$

A $\mathrm{T}$ the fourth meeting of the International Committee A of the Carte du Cicl, which took place at the Paris Observatory in May, under the presidency of M. Tisserand, the following members were present: MM. Anguiano, Bailland, Bakhuyzen, Christie, Donner, Duner, Gill, Henry (Paul), Henry (Prosper), Loewy, Rayet, Ricco, Trépied, Turner, Viniegra. There were also present at the invitation of the Permanent Committee, MM. Abney, Backlund, Bouguet de la Grye, Callandreau, Common, Cornu, Downing, Fabre, Faye, Gautier (P.), Jacoby, Knobel, Laïs, Laussedat, Newcomb, Perrotin, Scheiner, Stephan, Wolf.

Of the eighteen observatories associated for the production of the Carte du Ciel, thirteen were represented. The directors of the five other observatories, MM. Russell (Sydney), Baracchi (Melbourne), Obrecht (Santiago), Cruls (Rio Janeiro), Beuf (La Plata), were prevented from attending by great distance or by professional duties.

The following officers were elected: President, M. Tisserand; Vice-Presidents, MM. Bakhuyzen and Gill; Secretaries, MM. Donner and Trépied.

The following resolutions were adopted :--

\section{I.--Photographic Catalogue.}

r. The Committee is of opinion that the probable error of the value of the rectilinear coordinates measured on the plates should be reduced to the smallest possible limits, and that the measurements must be directed in such a way that this probable error shall never exceed $\mathrm{o}$ " 20 .

2. (a) The Committee thinks it necessary to publish the rectilinear coordinates of the photographed stars as soon as possible.

(b) It is desirable that this publication should include the necessary information for the conversion of the results into equatorial coordinates.

(c) The Committee desires that a provisional catalogue of right ascensions and declinations should be published by those observatories which have sufficient funds at their disposal.

3. Each observatory will be at liberty to choose the positions of the comparison stars in the catalogues which seem to them most suitable. For the calculation of the constants of a plate, a minimum of ten comparison stars should be adopted if possible. The adopted positions of these comparison stars will be published.

4. The question of determining whether, for the reduction of the stars to I900, it would be advisable to adopt a uniform system of constants for the observatories, will be the subject of a subsequent discussion.

5. The Committee recommends the adoption of a uniform size of publication for all the observatories; the size should be that of the volumes of the Catalogue of the Paris Observatory.

1 Abridged from the Bulletin Astronomique, July 1896 .

NO. I 398 , VOL. 54]
6. The observatories will be at liberty to determine the photographic magnitudes, either by measurements or by estimation. The only condition which the Committee thinks it necessary to impose, is that the system of photographic magnitudes on which the measures or estimations depend, should allow of a precise definition, so that the different scales used in the different observatories can be reduced io a common system.

\section{II.-The Photographic Chart.}

7. Every observatory will be provided with a scale of density, which will be printed on the plates at the same time as the réseau, and which will permit the determination of the sensibility of each plate for luminous sources of different intensities.

Captain Abney is charged by the Committee with the construction of the scales.

8. For the construction of the chart, the second series of negatives (that is to say, those of which the centres have odd numbers for their declinations) will be made in three exposures, each lasting thirty minutes. This time of exposure may, of course, be reduced if an increase of the sensibility of the photographic plates be secured.

9. The Committee allows photogravure on copper as a means of reproducing the chart. The negatives to be exposed three times, and enlarged to twice the original size.

Io. The observatories will make two positives on glass by contact, one of which will be placed in the Pavillon de Breteuil, the headquarters of the International Bureau of Weights and Measures.

II. The Committee defers till the next meeting the examination of the measures which it may be necessary to take with the object of assisting those observatories which may anticipate a difficulty in completing their programme.

The meetings of the Committee were marked with the greatest cordiality, and with the desire to carry to the end the great work undertaken in common; the decisions, prepared by special sub-Committees, were passed unanimously by the members present.

The Conference was followed by a soirée on Saturday, May I6, and by a dinner given the next day (Sunday, May I7), in the large gallery of the Observatory, at which the following were present: MM. Rambaud, Minister of Public Instruction; Bertrand and Berthelot, Permanent Secretaries of the Academy of Sciences; Cornu and Chatin, President and Vice-President of the Academy ; the members of the Committee, and numerous visitors belonging to the Academy, the Bureau des Longitudes, the Council of the Observatory, and the personnel of the establishment. Prof. Backlund, Dr. Downing, and Prof. Newcomb, members of the Conference on fundamental stars, were also present.

\section{NOTES.}

Lieutenant de Gerlache announces that the Belgian Antarctic Expedition he has been organising for some time past will not be sufficiently advanced to start before next year.

M. Eugène Tisseranis will shortly retire from the post of Director-General of Agriculture in France, after forty-six years of public service.

Extremely hot weather is reported from North America. In New York, on Tuesday, the shade temperature reached $97^{\circ} \mathrm{F}$. As many as 226 deaths are recorded as being directly 'due to this abnormally high temperature. In Chicago there were fifty-one deaths on Monday, and twenty-five on Tuesday. Hundreds of dead horses are said to be lying in the streets. The thermometer registered $96^{\circ} \mathrm{F}$. at Ottawa. 